\title{
A practice of one day's training course of information literacy for teachers in Japan: case study of Waseda University
}

\author{
Koichi Yukishima ${ }^{1}$ and Kazuyuki Sunaga ${ }^{2}$ \\ Waseda University ${ }^{1}$, Kokugakuin University ${ }^{2}$ \\ Japan, \\ yukis@waseda.jp¹ sunaga@kokugakuin.ac.jp²
}

\begin{abstract}
The training course of information literacy for teachers started in 2012 at Waseda University and has been carried out in August in the last four years. The course titled "Preparing class plans using school library" is a part of courses for renewal of teachers' certificate. Most of them are subject teachers who aren't in charge of school library even though a few are teacher librarians. The aim of the course is to identifier the nature of information literacy, to realize some skills, and to apply each skill for their curriculum. We explain some models of information literacy, ex. ISPA model, Big6 model and PLUS model. We provide them a kind of workshop. Supposed students in digital age, we are going to adopt not only materials based on paper but also new technology, for example, Web2.0 for the training course in future.
\end{abstract}

Keywords: Information literacy, Workshop, Training course

\section{Introduction}

In Japan, as the teachers' certificate law was reformed in June 2007, the term of the teachers' license shall be ten years from its issue or its renewal. For the renewal of their certificate, they should take the courses for renewal of teachers' certificate in university and so on. According to the reform of the teachers' certificate law, the courses for renewal of teachers' certificate commenced in the School of Education in Waseda University in the 2009 academic year. This School has educated a lot of educators until now. At the beginning of the courses, these course had been conducted in late December because it would be before the winter holidays. They had been conducted during the third week of August since the 2012 academic year. But there 
were a lot of complaints because the trainees should prepare for the fall term in the third week. Since the 2014 academic year, they have been conducted during the first week of August. We are planning to organise a practical course concerning the preparation for class plans with using school library in the courses for renewal of teachers' certificate. The reason is that the using of school library is essential for some subjects as stated in the curriculum guideline in Japan. We realised that the practical course concerning using of school library is crucial for the renewal of teachers' certificate. Then Yukishima has collaborated with Sunaga to organise a program titled "Preparing class plans using school library" since the 2012 academic year. We report its three years of the performance and issues (Yukishima \& Sunaga, 2015).

\section{Plan and design the program "Preparing class plans using school library"}

One of the educational policies in the current curriculum guideline is that students need to acquire fundamental knowledge and skills to consider, to determine and to solve independently.

The general policies in current curriculum guideline of the elementary school (MEXT, 2008), for example, states:

"In providing educational activities, each school should create specifically tailored educational activities by making use of originality and ingenuity, in order to foster in pupils a zest for life. In doing so, each school should be committed to enhancing its instruction to enable pupils to solidly acquire basic and fundamental knowledge and skills, to foster the ability to think, to make decisions, to express themselves and other abilities that are necessary to solve problems by using acquired knowledge and skills, to cultivate an attitude of proactive learning and to develop pupils' individuality. In working toward these goals, each school should enhance its pupils' language activities, giving consideration to the developmental stages of the pupils, and in cooperation with pupils' homes at the same time, consideration should be given to help pupils establish good learning habits."

To utilise the school library is a way to provide students opportunities to solve a problem. The current curriculum guideline of the elementary school (MEXT, 2008) states "Effort should be made to utilize the school library and its functions in a well-planned manner to give pupils better opportunities to carry out independent and self-motivated learning and reading activities." In other words, it is necessary that teachers should transform programs in classroom to encourage students to solve problems through exploring information with using resources in school library. However, it is difficult for subject teachers to teach with using 
resources in their library. Because teachers usually rely on textbook to instruct their students and there is a short stock suitable for students in school library.

Recently we are able to find some cases that teachers work with school library staff in their library in elementary schools and junior high school. Unfortunately, there are a few case that high school teachers instruct students with resources in school library. That implies that it is still crucial for teachers to work with using resources in school library. We argue that teachers would improve planning an instruction for their students once they are able to experience a practical program with using resources in school library.

In the School of Education of Waseda University, Sunaga has been teaching the information literacy and learning models in the subject titled "the Learning and School Library" as part-time lecturer. Yukishima has been teaching with a kind of workshop in the subject titled "the Practices of Social Education" as exclusive professor in Waseda University.

We should have challenged to solve some problems for organising the program. There is not a school library in Waseda University. The one of libraries in university is, however, useful for students who belong to the School of Education. The collection of this library is suitable for students who will become a teacher in secondary school. There are approximately 56,000 books in the library. We considered this library as school library in secondary school. At same time we resigned to accept teachers working in elementary school because the books are unsuitable for elementary school's students. We could utilise the wireless LAN in this library. The trainees could use computer and access to the internet in order to search the proper information.

We have insufficient time and room to organise the program. It is necessary that trainees understand a range of information skills and they apply these skills to the practices in the program. We would need enough time to do all. It would be convenient to move alternately between a lecture room and a work space as short time as possible. Fortunately, the library using as work space would be close to the lecture room. We would be able to accept thirty trainees as the lecture room have a sitting capacity. We made the proper number of trainee for doing a kind of workshop.

We were organising for a program in one day's workshop to identifier a range of information skills and to use them. We determined the framework of five items. 1. Guidance: the purpose and aim of this training program, a guide of the library, 2. Outline of the information literacy: explanations about the models, 3. Workshop: planning a program using resources in school library and webs exiting outside the school, 4. Presentation and evaluation: exchanging of opinions, and 5. Drawing up personal report. We would design a program in Table 1. 
Table 1: The timetable of "Preparing class plans using school library" in Waseda University

\begin{tabular}{|c|c|c|}
\hline 09:30-10:20 & Guidance & $\begin{array}{l}\text { The purpose and aim of the program \& } \\
\text { workshop. Guide of the library. }\end{array}$ \\
\hline $10: 20-10: 30$ & Break & \\
\hline $10: 30-12: 00$ & Outline & $\begin{array}{l}\text { Aspects of information skills: Brainstorming, } \\
\text { Concept-Mapping, Methods of searching } \\
\text { information, Skimming \& Scanning, Selection } \\
\text { of information, Presentation and Evaluation. } \\
\text { Based on the PLUS model (Herring, 1996) }\end{array}$ \\
\hline 12:00-13:00 & Lunch & \\
\hline $13: 00-14: 30$ & Group work & Designing of a teaching plan. \\
\hline $14: 30-14: 40$ & Break & \\
\hline $14: 40-16: 00$ & Group work & Preparation of their presentation. \\
\hline $16: 00-17: 00$ & Presentation & Poster session and Exchanging opinions. \\
\hline $17: 00-17: 10$ & Break & \\
\hline $17: 10-17: 50$ & Report & Drawing up personal report. \\
\hline $17: 50-18: 00$ & Summary & Comments. \\
\hline
\end{tabular}

\section{The outline of the program}

In the morning we emphasized the significance of school library and information literacy in the current curriculum guideline in Japan, and stated the purpose and aim. The purpose is to learn how subject teachers use the resources in their library. The aim is to encourage the trainees to design a plan of lesson in group. We introduced them to the lecture room, the library and the work space, and how to search information by computer.

We have adopted a translation of Teaching Information Skills in School (Herring, 1996) as textbook to help the trainees to understand information literacy in limited time as one hour and a half. Sunaga translated Herring's book into Japanese in 2002. We tried to make them to identifier a range of information skills through the process of Herring's PLUS model in textbook. Because most of teachers have not perceived the essence of information literacy but knowing merely the phrases in Japan.

The PLUS model consists of four steps which a range of information skills are integrated; Purpose, Location, Use and Self-evaluation. 
About thirty trainees should be divided to six groups because a small group is easy to talking together. First of all, the facilitator ordered the trainees to write down Japanese onomatopoeic words which express the library they have experienced. Next they were talking about the onomatopoetic words in five minutes. The respective group announces their words. It is a kind of brainstorming. For example, "Shiin" would express a silent atmosphere. In other words, there would have been no soul in school library. "Wai Wai" would express a lively and bustling air or, to put it another way, their students must have used school library. The way using by the onomatopoetic words made them to focus on libraries. We consider it as the best way to encourage the trainees to reflect on school library. Most of them were subject teachers who teach Japanese, English language, history and another subjects. Some would be teacher librarians or some would be in charge of school library.

We explain each stage in Herring's PLUS model. In the step of Purpose, the trainees are encouraged to consider a topic of their task and the way to find information. We gave them a topic, for example "Earthquake" and they would try to do the brainstorming again. They wrestled the brainstorming enthusiastically. We were collecting the words concerning the topic of earthquake and made a concept map on the white board. They could have recognised the brainstorming and the concept mapping to identify their topic.

They would be encouraged to reflect how to find information about the topic identified. With looking for information about the earthquake, students would rush to their library and look the words up in encyclopaedia or should ask a researcher in the laboratory. In the program they were looking for books, encyclopaedia and reference tools around the library. Some of them were searching for information on web.

In the step of Use in the explanations of PLUS model, we highlighted students' reading with text. Finding information is only one part of information literacy. In Japan they have put emphasis on finding information out of books in cross curriculum. The trainees would be encouraged to read a passage on handout in a short time, or a couple of minutes. That passage is extracted from Glory and Collapse of Genius: Several Scholar Biographies written in Japanese by Masahiko Fujiwara (2002). The boyhood of Isaac Newton is described in the passage. That is a lovely story. Newton was a bullied boy and one day he had a big fight against his enemy. His enemy surrendered to Newton. Newton was a son of farmer's family but so hard to study mathematics that he could be admitted to the University of Cambridge. Before trainees read the passage, they were suggested to find a keyword out. The keyword is "Newton". We pointed out that is skimming. Next the trainees quickly read the passage again to find out matters of his boyhood. We pointed out that is scanning. 
We pointed out the significance of students' self-evaluation in the PLUS model. Students need to reflect the process and performance of their work. Their reflection would lead them to next success. We suggested that they should form a checklist described in the PLUS model. The checklist for their students is based on the Whitaker's theory (Whitaker, 1995). In the investigative learning students have been searching information in books, taking a note, writing their report or making their presentation in Japan. They have repeated the circle of this investigative learning without a reflective practice. Rather to say this circle is Whitaker's "Incidental learning route". Students often missed a clue to modify their project. This is seemed to cause university students to repeating a copy-and-past. Teacher will need to give opportunities to reflect the project to his/her students if their learning is more effective. Whitaker's "Deliberate learning route" is the process which composed of reflecting on the project, drawing conclusions, considering new possibilities and making plan.

In the afternoon the trainees would decide their topic in group with brainstorming. Their topics should be related to subjects which they teach in school. They would produce a poster for their presentation. They could make a concept map where their topic is centred on the poster. Their topic connected to each key word writing on a label (post-it) with masking tape on the poster as Figure 1. This will make their posters creative and plastic. They were collecting books relevant to their topic.

Ideally, each trainee should create his/her presentation using by the information and communication technology and on web. Unfortunately, we had insufficient time to use a personal computer per trainee the past four years. There are a quite few expert teachers at handling the software and webs. For the future we will suggest trainees to utilise a wiki and a tool of Web 2.0 for their presentation (Herring, 2011).

Each group of trainees made a presentation using by their poster in 10 minutes. They were forced to evaluate the presentation of another group simultaneously.

At the end of the program they would draw up a short essay of information literacy all through their practices. Their essays should be graded after the program. 


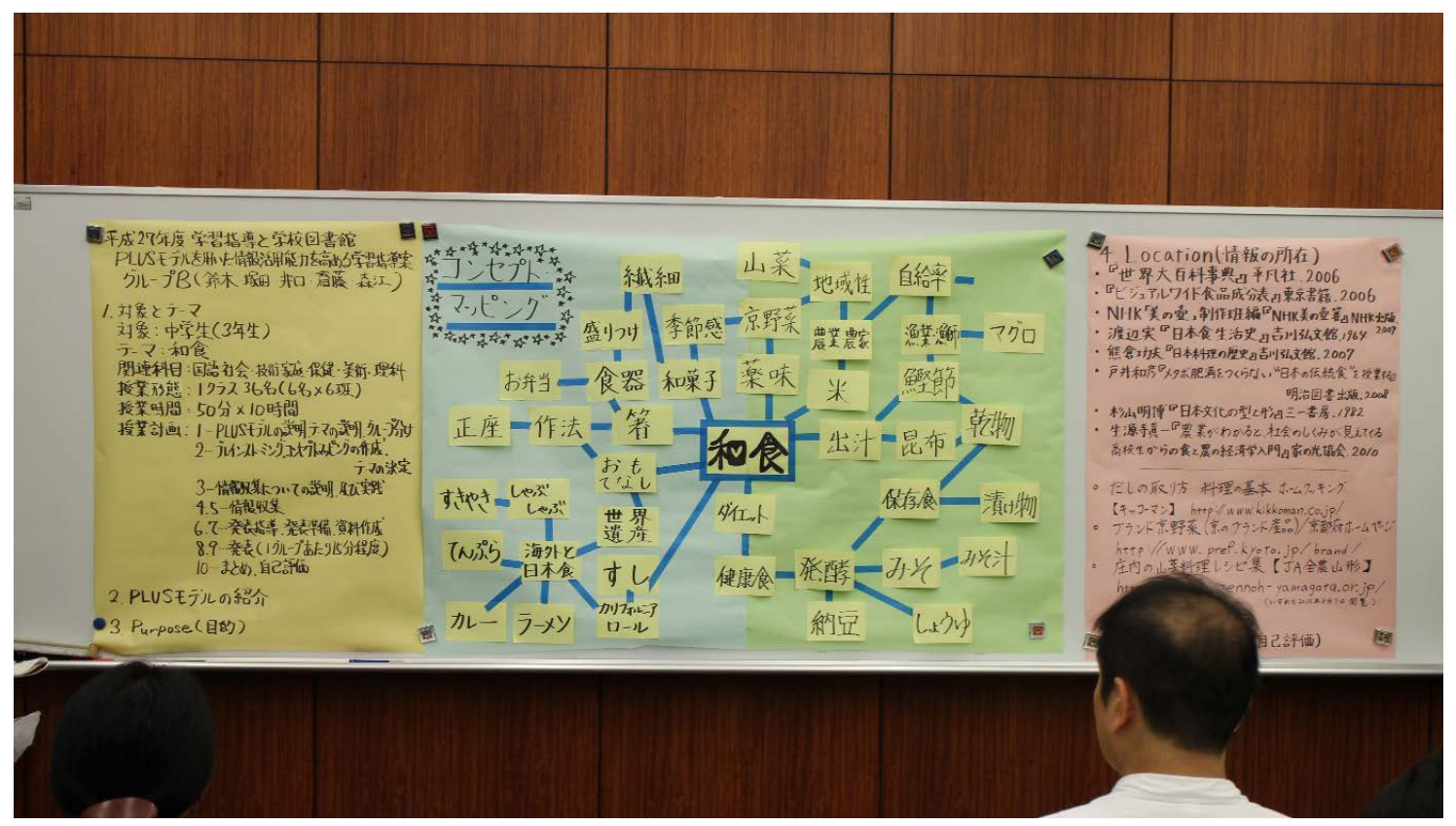

Figure 1. An example of poster session "Japanese cuisine"

\section{The training courses in past four years}

We report the training courses in past four years

\section{2's training course}

The number of trainees was thirty.

The topics: Foods (eating habits and nutrition), the Olympic games, Kansai region (Kyoto, Nara and Osaka. Visiting places of school excursion), the Graduation, Britain.

Trainees' comments:

"I realised we need to utilise our school library with our students effectively."

"As I was very charmed with the brainstorming, I was getting to motivated to learn."

"As we used the library (in Waseda University), having a change of perspective to school library, I would like to utilise our school library with students."

"I was getting open-minded because of so many opinions in group work"

'If we were planning this program with using library, students' friendship would develop deeply as they use increasingly library."

"As I experienced both a situation of student and one of teacher, I was deeply educated through the practice of the PLUS model."

\section{3's training course}

The number of trainees was thirty. 
The topics: the cellular phone, the mail, the club activities (the extracurricular activities), Tokyo (Visiting places of school excursion), Mt. Fuji, Bento (lunch box).

Trainees' comments:

"Though we usually use the resources in school library for teaching subjects, we were unable to improve on sessions which would make students' learning independently. I could find educational tips."

"I would like to adapt our instructions to the PLUS model."

"I was satisfied that we could complete a planning class in group. Coming back to our school, I would like to try a such project."

"I exchanged opinions in group work with teachers from other regions and from different kinds of school. I was satisfied that we made a presentation together."

"All through the workshop I was able to examine what topic is easy or difficult to broaden."

"I was educated all through the practices in group. I recognised the concepts of the PLUS model."

\section{4's training course}

The number of trainees was twenty-nine (One absent).

The topics: the monsters and ghosts, the summer, the school, the childcare, Columbia, the health.

Trainees' comments:

"We would like to apply this program to a wide variety of fields as topic learning and prior learning of school excursion."

"I was contented that we challenged a kind of workshop in group instead of lecture. I am planning to adapt our instructions to this program."

"I was satisfied that I could experience a planning class in group together with new teachers."

"This was a very practical program. I realised how to instruct students. I am hoping to plan a session using the resources in school library."

"I was contented that I was working with teachers from different kinds of school. Investigating with books, I recognised the books in the library with more detailed."

"I was so satisfied with the workshop that I forgot about time passed away. I admired the presents by the other groups"

\section{5's training course}

The number of trainees was twenty-eight.

The topics: Okinawa, Japanese cuisine, Shizuoka Prefecture, Sumo wrestling, Working, the anniversary of the end of World War II. 
Trainees' comments:

"I learned the practice of the framework of PLUS model and I think of trying to practice it in the school. I am accustomed to using of the library and web sites, so I could study it willingly."

"I forgot time passed away during the group work studying the PLUS model with new acquaintances."

"I could study delightfully and understand considerably the PLUS model as information skills through the workshop."

"Because this course was the learning with using the school library, it seemed that it would be able to do immediately. It served as a reference that presentations of the other groups could be heard and were interesting respectively."

"I encountered the PLUS model and could realize it. However, it was not easy to understand whether we would make an instructive plan or we would research the topic."

"We could practically learn a series of process of the information utilization. I have already learned how to search information and studied the effective instruction of exchanging opinions, but it was the first time for me to know the step-by-step approach of the instructive model."

\section{Conclusions}

Information literacy is a key issue to challenge in our educational environment. We continued to develop the training program for renewal of teachers' certificate during summer in Waseda University. In summary most of participants evaluated the effectiveness and instructiveness of our workshop. However, there remained some negative comments:

"We were too pressed for time to do everything."

"You should have concentrated your discussion on the PLUS model."

"What was our goal? It was for us too difficult to understand that."

"It was seemed to me that the aim in our textbook would differ from the Purpose in the PLUS model. So I was too confused with the difference."

"I was eager to take the lecture's experiences on his practices."

These comments demanded some improvements on our program in Waseda University.

- Temporal restriction: As we should reduce the hours of the guidance on the training course, we would increase the hours of the workshop in proportion of the saving the guidance.

- Emphasis on the PLUS model: We should put an emphasis on the PLUS model. We should show the utmost consideration for the trainees so as to deepen their understanding of the model. We would like rather to show them the significance of information literacy.

Regarding the information literacy, it is seemed that the skills to use the resources in library is equivalent to the abilities to manipulate a computer. Even if there is only a slight difference. 
- Utilisation of the ICT: The technologies of the web made rapid progress in $21^{\text {st }}$ century.

The use of the ICT is the heart of our life. We are surrounded with the new technologies. In geophysics, the components of the earth are divided into four areas; the lithosphere, geosphere, hydrosphere and atmosphere. We could add the biosphere where all of living things exit. Now the ICTs will transform our life into the technosphere or the cybersphere. Some participants were hesitant to search information by computer in 2012 because they would instruct students without computer. Gradually trainees have been willing to use the OPAC in Waseda University. In 2014 most of them mastered computer and tools on web with little explain.

Teachers, school library staffs and students will utilise not only the resources in the library but also on web. We will challenge to literate computer with the participants because we faced on the digital age. We will adopt Herring's new book Improving students' web use and information literacy: a guide for teachers and teacher librarians (Herring, 2011) in this summer.

\section{References}

The Ministry of Education, Culture, Sports, Science and Technology (2008, written in Japanese). The curriculum guideline of the elementary school. (2011, written in English) http://www.mext.go.jp/component/a menu/education/micro detail/ icsFiles/afieldfile/20 $\underline{11 / 04 / 11 / 1261037 \text { 1.pdf }}$

Herring, James E. (1996). Teaching information skills in schools. London: Library Association Publication.

Whitaker, Patrick (1995). Managing to learn: aspects of reflective and experiential learning in schools. London: Cassell.

Yukishima, Koichi \& Sunaga, Kazuyuki (2015). Course for teacher's certificate renewal "Preparing class plans using school libraries". Libraries Today, 53(1). 32-38 (written in Japanese)

Herring, James E. (2011). Improving students' web use and information literacy: a guide for teachers and teacher librarians. London: Facet.

\section{Biographical note}


Author 1: Koichi YUKISHIMA has worked as Professor at Waseda University in Tokyo, Japan since 2013; the main research is the library and information science, bibliography and history of the book.

Author 2: Kazuyuki SUNAGA has worked as Professor at Kokugakuin University in Tokyo, Japan since 2013; the main research is the school librarianship and the library and information science. 